\title{
Arsenene, antimonene and bismuthene as anchoring materials for lithium-sulfur batteries: a computational study
}

\author{
Xiaotong $\mathrm{Mao}^{1}$, Lin $\mathrm{Zhu}^{1}$, and Aiping $\mathrm{Fu}^{2}$ \\ ${ }^{1}$ Qingdao University \\ ${ }^{2}$ State Key Laboratory of Bio-Fibers and Eco-Textiles
}

December 31, 2020

\begin{abstract}
Finding effective anchoring materials for the immobilization of soluble lithium polysulfides to suppress the shuttling effect has become the key to large-scale application of lithium-sulfur ( $\mathrm{Li}-\mathrm{S})$ batteries. In this work, the potentials of group-VA two-dimensional (2D) materials including arsenene, antimonene and bismuthene (As, Sb and Bi monolayers) as Li-S battery cathode anchoring materials were systematically investigated by density functional theory (DFT) calculations. The adsorption energies of sulphur ( $\mathrm{S} 8$ ) and various lithium polysulfides (Li2Sn, $\mathrm{n}=8,6,4,2,1$ ), as well as the diffusion energy barriers for long-chain Li2S4 and Li2S6 on these three monolayers were studied in detail. The calculated moderate adsorption energies of these monolayers to all polysulfides imply that they can effectively inhibit the shuttling effect. The favorable diffusion barriers for Li2S4 and Li2S6 ensure the efficient diffusion of polysulfides on monolayer surface. In addition, these 2D materials can keep a balance between the binding strength and the structural integrity of polysulfides. The presented merits demonstrate that As, $\mathrm{Sb}$ and $\mathrm{Bi}$ monolayers can be the promising cathode anchoring materials to improve the performance of Li-S batteries.
\end{abstract}

\section{Hosted file}

Main document-2020-12-20.pdf available at https://authorea.com/users/386472/articles/501951arsenene-antimonene-and-bismuthene-as-anchoring-materials-for-lithium-sulfur-batteriesa-computational-study

\section{Hosted file}

images-2020-12-22.pdf available at https://authorea.com/users/386472/articles/501951arsenene-antimonene-and-bismuthene-as-anchoring-materials-for-lithium-sulfur-batteriesa-computational-study

\section{Hosted file}

tables1-2-2020-12-22.pdf available at https://authorea.com/users/386472/articles/501951arsenene-antimonene-and-bismuthene-as-anchoring-materials-for-lithium-sulfur-batteriesa-computational-study 